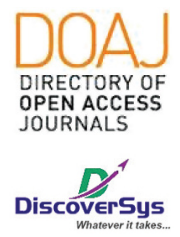

Published by DiscoverSys

\section{Three-port laparoscopic sleeve gastrectomy: serial cases report}

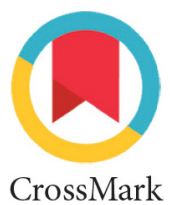

\author{
Gede Eka Rusdi Antara ${ }^{1 *}$, Maria Yustina²
}

\section{ABSTRACT}

Background: Laparoscopic sleeve gastrectomy is the procedure of choice for bariatric surgery. It is a minimally invasive procedure that giving good outcome and less complication compared to other procedures. The multiport sleeve gastrectomy technique is usually described by using 4 to 6 ports and an additional port for a liver retractor. Single-incision laparoscopic sleeve gastrectomy was reported, but not widely adopted.

Objective: To describe a convenient and applicable modified technique of three ports laparoscopy for sleeve gastrectomy that may give better outcome and cosmetic.

Cases: Four patients were diagnosed with obese class II and III. Upper $\mathrm{Gl}$ study was performed before surgery. We performed three ports laparoscopic sleeve gastrectomy. The $15 \mathrm{~mm}$ port was placed in the umbilical, for the camera. The second $12 \mathrm{~mm}$ port was placed in the right side of the umbilical for the stapler, and the third port, $5 \mathrm{~mm}$ was placed in the right hypochondrium midclavicular line. During the surgery, we used endoscope as guidance during gastric stapling and also for evaluation the stapler line and the size of the stomach. The postoperative condition was uneventful, the patients have less scar and less length of stay.

Conclusion: Three ports laparoscopic sleeve gastrectomy is easy to perform, convenient and applicable, consume less time and also give excellent results for the patient's recovery.

Keywords: obesity, laparoscopic sleeve gastrectomy, three ports

Cite This Article: Antara, G.E.R., Yustina, M. 2019. Three-port laparoscopic sleeve gastrectomy: serial cases report. Intisari Sains Medis 10 (2): 471-474. D01: 10.1556/ism.v10i2.427

\section{INTRODUCTION}

'Digestive Surgery Division, Surgery Department, Faculty of Medicine, Universitas UdayanaSanglah General Hospital Denpasar, Bali-Indonesia ${ }^{2}$ General Surgery Resident, Surgery Department, Faculty of Medicine, Universitas Udayana-Sanglah General Hospital Denpasar, BaliIndonesia

*Corresponding to: Gede Eka Rusdi Antara; Digestive Surgery Division, Surgery Department, Faculty of Medicine, Universitas Udayana-Sanglah General Hospital Denpasar, BaliIndonesia

dr_rusdi@yahoo.com

Received: 2019-07-30 Accepted: 2019-07-28 Published: 2019-08-01
Obesity has reached morbidity of up to 15 million people in the United States and has become a concentration on community health that needs more attention. The prevalence of obesity in the United States shows $34.4 \%$ of the population is obese class I and $6 \%$ are obese class II. Obesity is also associated with many comorbidities that significantly reduce life expectancy. ${ }^{1,2}$ Surgical intervention has become the most effective treatment option for reducing morbidity in obese patients who can have longterm weight loss effects and limit drug use. ${ }^{3,4}$

A report from the Swedish Obesity Subject study, which is a prospective cohort study that provides ten years of follow-up, shows bariatric surgery has a relationship with long-term weight loss and a reduction in mortality rates in obese patients. Bariatric surgery techniques have been highly developed over the past few years, so that this operation is safely carried out has a very good effective cost value for long-term weight control. ${ }^{2,3}$

Bariatric surgery techniques in this era show that there are three choices of surgical techniques that are the main choices, namely Laparoscopic sleeve gastrectomy (LSG), laparoscopic adjustable gastric band (LAGB), and laparoscopic rouxen-Y gastric bypass (LRYGB). ${ }^{1,4}$

Laparoscopic sleeve gastrectomy has become the most commonly performed weight-loss operations over the last few years. The sleeve gastrectomy technique was first described as part of the duodenal operation switch. Gagner and Petterson who first reported total laparoscopic duodenal switch operation. Then Chu et al. who developed the use of LSG as the first stage of bariatric surgery for super obese patients. Based on recent studies, LSG is not only a safe, but also an effective bariatric procedure with long-lasting results. The LSG is essentially a restrictive bariatric operation. Weight loss is achieved by drastically reducing the gastric volume, which in turn leads to reduced food intake. Also, a series of hormonal changes occurring postoperatively in bariatric patients, contribute to decreased appetite, reduced food intake and longterm weight loss. ${ }^{1,4,5}$

At the time of its development LSG was performed through six 10 to $15-\mathrm{mm}$ ports. Currently, the most widely practiced multiport technique for LSG uses 4 to 6 ports with an additional incision for a liver 
retractor. ${ }^{2}$ This case report will provide an overview of LSG management conducted at our center, Sanglah General Hospital, Bali-Indonesia.

\section{CASE PRESENTATION}

We performed three ports laparoscopic sleeve gastrectomy to 4 patients. Three females and one male, diagnosed with Obese class II and III. First patient, female, with BMI $39.8 \mathrm{~kg} / \mathrm{m}^{2}$ and has

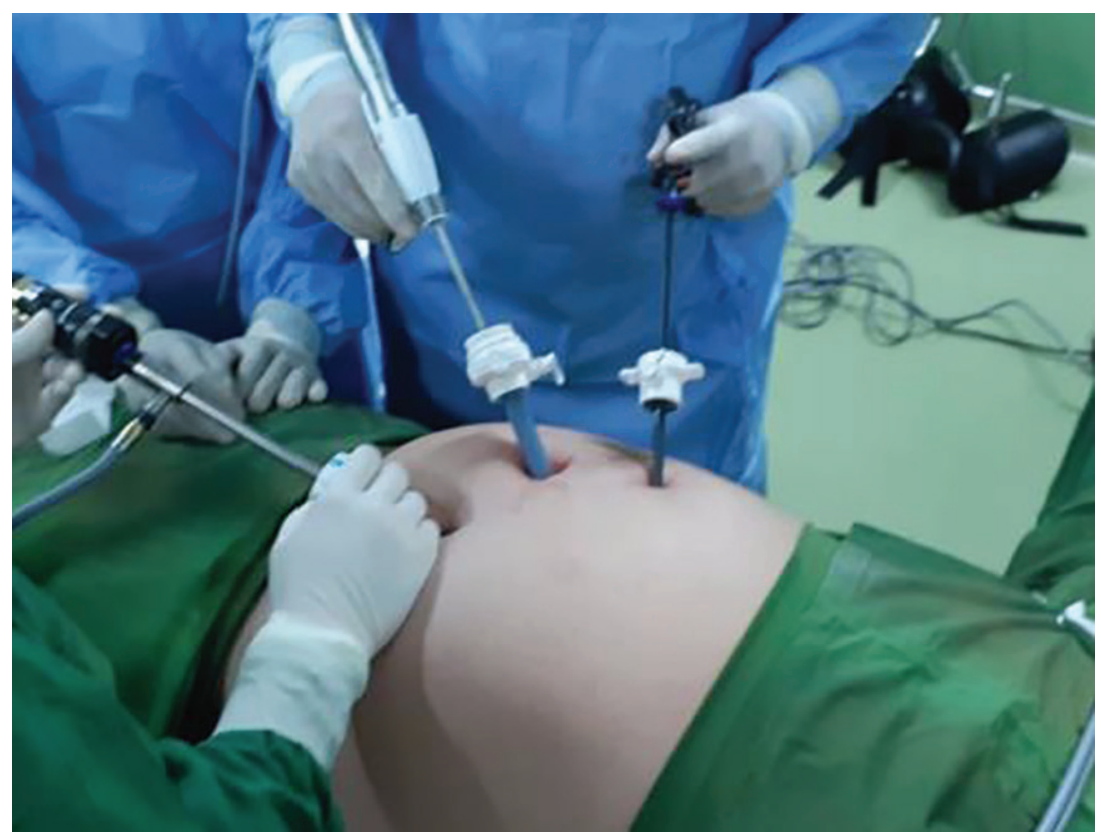

Figure 1. Three ports position

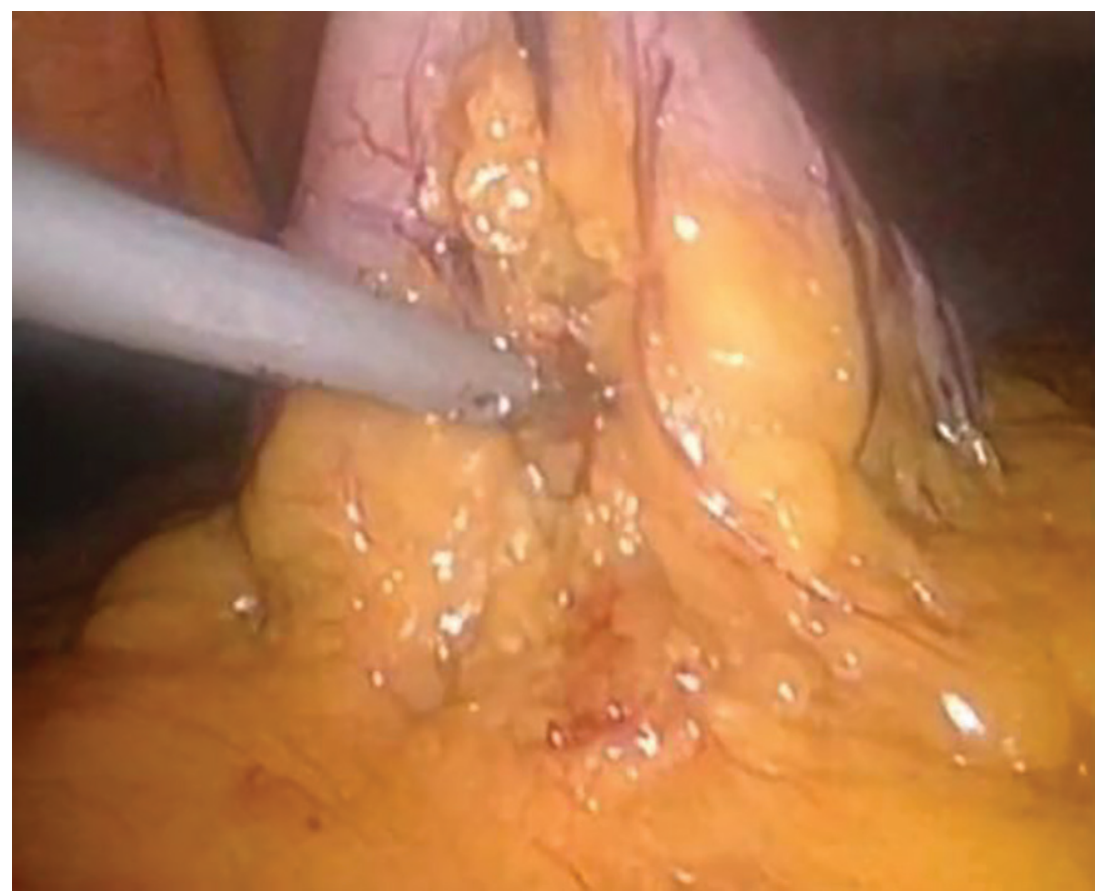

Figure 2. Dissection of greater curvature hypertension and sleep apnea, second patient, male with BMI $41.74 \mathrm{~kg} / \mathrm{m}^{2}$ with diabetes mellitus as comorbid and gets routine long-acting insulin injection. Third patient was female, $46.9 \mathrm{~kg} / \mathrm{m}^{2}$ with osteoarthritis, low back pain, sleep apnea and also hypertension. The fourth patient was female with BMI $37.6 \mathrm{~kg} / \mathrm{m}^{2}$ with hypertension and diabetes mellitus under treatment. All of them were planned to have laparoscopy sleeve gastrectomy.

During the procedure, the patient was in supine position under general anesthesia. A urinary catheter was inserted and stockings compression for DVT prevention were applied. The patient also gets enoxaparin subcutaneously as prevention for DVT and pulmonary embolism. The laparoscopic set was positioned at the right side of the patient, there were two laparoscopy screens, on the right side of the patient and at the head of the patient on the left side. The endoscopic set was positioned at the head of the patient on the right side. The surgeon stood on the right side and the assistant stood on the left side. The instrument table was positioned at the foot of the operating table. Before surgery, we performed upper GI study per endoscopy for evaluation. From endoscopy examination, for all of the patients, the results were within normal limit, no ulcer, mass, or GERD was found. We made incision on the umbilicus. The $15 \mathrm{~mm}$ optical view trocar was inserted into abdominal cavity through the umbilical, the abdominal cavity was insufflated, then the $15 \mathrm{~mm}$ camera was inserted. The second and the third trocars were inserted under vision of the camera. $12 \mathrm{~mm}$ port was placed in the right side of the umbilical for the stapler, and the third port, $5 \mathrm{~mm}$ was placed in the right hypochondria mid clavicle line (Figure 1).

We dissected great curvature approximately 3 to $4 \mathrm{~cm}$ below gastroesophageal junction to approximately $3 \mathrm{~cm}$ above the pyloric sphincter, continued with dissection of short gastric vessel. An atraumatic grasper was introduced through the right upper mid-clavicle to retract the omental, the dissection used an ultrasonic dissector (Harmonic Scalpel) through the right paraumbilical port (Figure 2).

We did endoscopy as guidance and inserted the scope to the pyloric and made gastric stapling along the greater curve close to the endoscope. We cut 50 to $70 \%$ of the stomach. The grasper retracted the stomach with left hand, the stapler was inserted into right paraumbilical port using right hand (Figure 3).

We needed 4 to 6 staple loads conventionally. Using endoscope, we evaluated the staple line for any bleeding, sign of leakage and also the size of the stomach. The excised stomach was removed 
through the umbilical port. The umbilical port's fascia and right paraumbilical fascia were closed. Skin incisions were closed. The postoperative condition was uneventful, the patients have less scar, better cosmetics appearance and were discharge in day 3 in good conditions (Figure 4).

\section{DISCUSSION}

Minimally invasive surgery has numerous advantages compared to open surgery, including

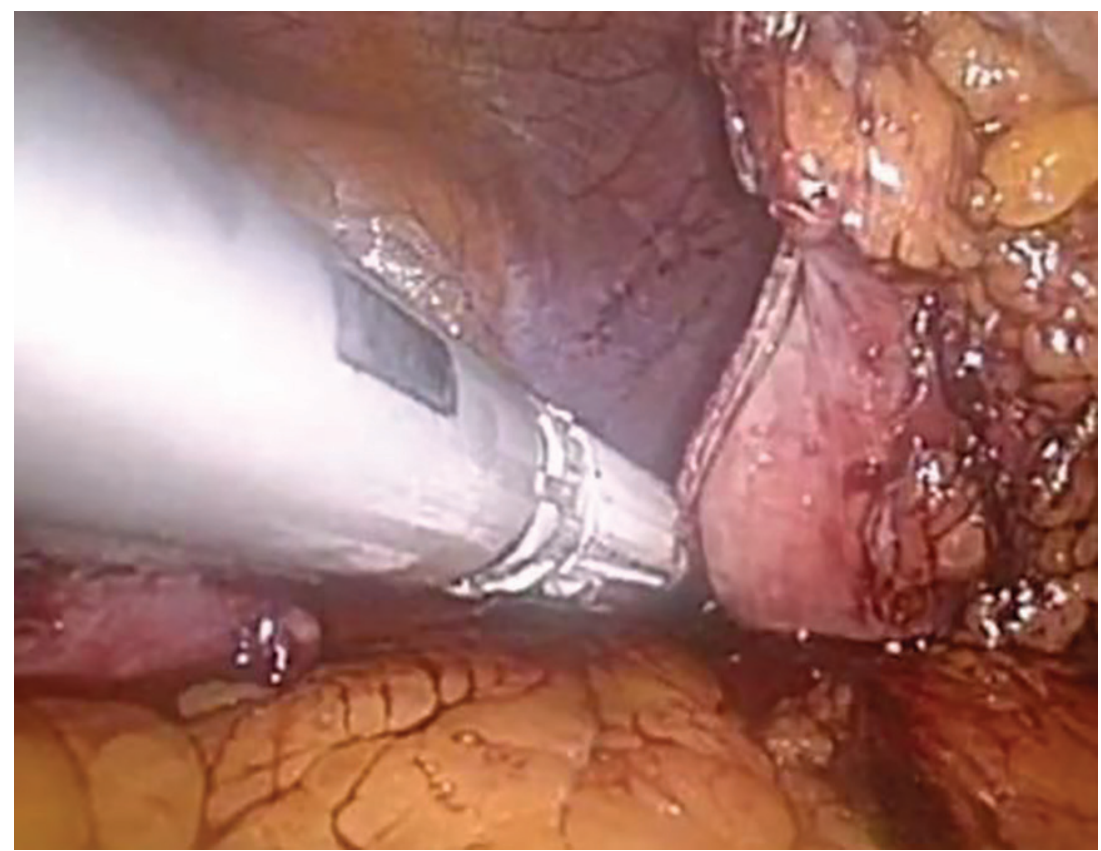

Figure 3. Gastric stapling

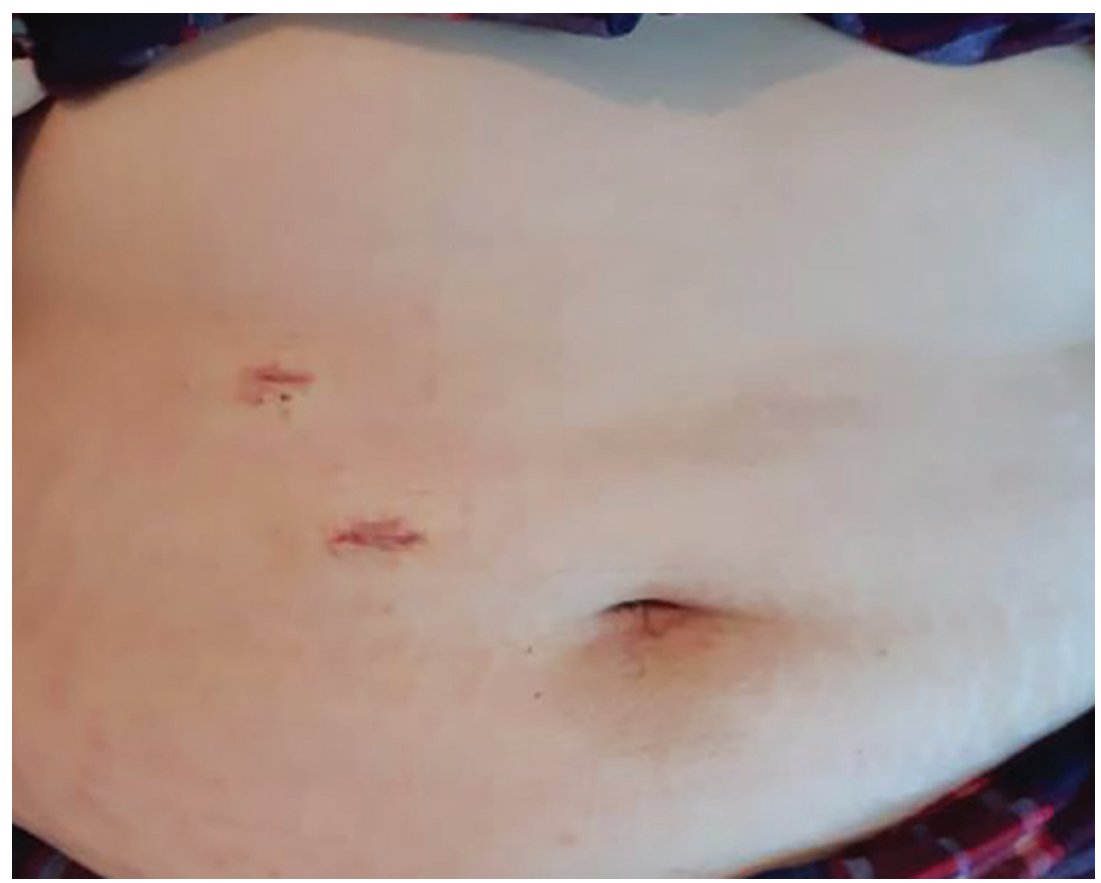

Figure 4. Postoperative wound decreased postoperative pain, less postoperative wound-related complications, shorten hospital length of stay, faster recovery, and better cosmetic results. Over the past few years, novel technologies have been developed that focus on even lesser invasive operative procedures. For instance, SILSSG (single incision laparoscopic surgery-sleeve gastrectomy) has been proposed to be safe and effective with good early postoperative results and less wound-related complications. ${ }^{6,7}$ However, the results of conventional multiport LSG are already excellent, and direct comparison with prospective randomized trials of SILS with conventional LSG is lacking. Currently, only one prospective comparative analysis has been published, and this study ( $\mathrm{n}=300$ patients in each arm) was done in carefully selected patients by highly qualified surgeons in SILS. At 2 years follow-up, Lakdawala et al. observed that SILSSG was less painful compared with conventional LSG, although all other variables (weight loss, resolution of comorbidities, and incisional hernia) were comparable in both groups. ${ }^{3,7,8}$

Several technical difficulties arise when utilizing the single incision approach. Navigating the complex instruments and loss of triangulation because of the limited area of movement can be inconvenient for the operating surgeon and can tend to make SILS-SG more difficult than conventional LSG. The size of the incision required in SILS is another concern due to the potentially higher incidence of wound-related complications, longer recovery, and even higher postoperative pain concerning the enlarged size. ${ }^{4}$ An "ideal" solution to the difficulties surrounding SILS SG may be the 3PSG technique. Potential advantages of 3 PSG over SILS-SG are better triangulation, no need for different instruments, and likely a shorter learning curve. The safety and feasibility of three port sleeve gastrectomy were initially reported by Arru et al. in a small prospective study studies present a larger sample size $(n=45)$ with satisfactory outcomes, specifically in LOS (mean $=2.7$ days), postoperative pain control (mean VAS $=2.6$ ), and cosmetic effect compared with the standard LSG data available. ${ }^{5,6,9}$

More postoperative pain, wound complications and the final cosmetic outcome remain the principal disadvantages of a multiport technique especially when many large trocars are used. The use of this 3-port technique in selected patients may bridge the gap and offset these disadvantages. ${ }^{7,10}$ The Three Ports Laparoscopic Sleeve Gastrectomy reduces the ports in number and size and subsequently the parietal trauma, it also an instrumental triangulation, making surgery safe and reproducible. ${ }^{5}$ 


\section{CONCLUSION}

Three ports laparoscopic sleeve gastrectomy is easy to perform, convenient and applicable, consume less time and also give good results for the patients.

\section{CONFLICT OF INTEREST}

The author declares there is no conflict of interest regarding publication of this report.

\section{ETHICAL ASPECT}

All patient has been signed informed consent and agrees for publication of their data as a case report article.

\section{REFERENCES}

1. Kehagias I, et al. Sleeve gastrectomy: have we finally found the holy grail of bariatric surgery? A review of the literature. European Review for Medical and Pharmacological Sciences. 2016; 20: 4930-4942

2. Galvani C, Choh M, Goroder M. Single-incision sleeve gastrectomy using a novel technique for liver retraction. JSLS. 2010;14:228-233

3. Lakdawala M, Agarwal A, Dhar S, Dhulla N, Remedios C, Bhasker AG. Single-Incision Sleeve Gastrectomy Versus Laparoscopic Sleeve Gastrectomy. A 2-Year Comparative Analysis Of 600 Patients. Obes Surg 2015;25:607-614
4. Marceau P, Biron S, St Georges R, Duclos M, Potvin M, Bourque R. Biliopancreatic Diversion With Gastrectomy As Surgical Treatment Of Morbid Obesity. Obes Surg 1991;1: 381-387

5. Arru L, et al. Three-port laparoscopic sleeve gastrectomy: feasibility and short outcomes in 25 consecutives super-obese patients. Cirugia Espanola. 2013;91(5):294-300.

6. Ako M. Laparoscopic sleeve gastrectomy on a morbidly obese patient with situs inversus totalis : A case study and systematic review of the literature. Obesity Researcg and Clinical Practice. 2016;12(2):148-54.

7. HayesK,EidG.LaparoscopicSleeveGastrectomy Surgical Technique and Perioperative Care. Surg Clin NA. 2016;96(4):763-71.

8. Jackson TD, Hutter MM. Morbidity and Effectiveness of Laparoscopic Sleeve Gastrectomy, Adjustable Gastric Band, and Gastric Bypass for Morbid Obesity. Adv Surg. 2012;46(1):255-68.

9. Brethauer SA. Sleeve Gastrectomy. Surg Clin NA. 2011;91(6):1265-79.

10. Aggarwal S, Kini SU, Herron DM. Laparoscopic sleeve gastrectomy for morbid obesity: a review. Surgery for Obesity and Related Disease. 2007;3:189-94.

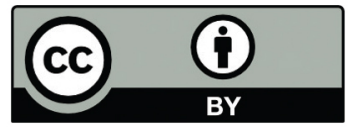

This work is licensed under a Creative Commons Attribution 